\title{
An interactive learning environment in Geographical Information Systems
}

\author{
Sarah Comelius and lan Heywood \\ Department of Environmental and Geographical Sciences, Manchester Metropolitan \\ University. Email: s.cornelius@mmu.ac.uk
}

The Unigis Learning Station is a computer-based learning management tool for the Postgraduate Diploma in Geographical Information Systems by distance learning (correspondence). Unigis is an international network of universities co-operating in the delivery of such courses. The students on Unigis courses are mature mid-career professionals who study in addition to undertaking full time jobs. The Learning Station offers these students information about the course, resources for independent study, a structured set of exercises, assessments and feedback opportunities, and an integrated and easy way to interact with other course software. Following a brief introduction to the Unigis curriculum, this paper discusses the design of the Learning Station. The roles the Learning Station adopts are outlined, and the range of multimedia and communications tools used discussed. Evaluation of the Learning Station is presented and the issued raised by this provide useful lessons for other computer-based learning management tools, and the adaptation of the Learning Station to other teaching and learning situations.

\section{Introduction: computer-based training and education in GIS}

Geographical Information Systems (GIS) are computer-based tools for the input, management, analysis, modelling and display of geographical data. GIS are applied in a wide range of organizations and disciplines, including central and local government, environmental agencies, transport planning and vehicle navigation, education and research, utilities management, resource management, and the financial and retail sectors. GIS is a field of constantly changing technology, and it has been recognized that GIS education needs to be more than a 'once in a lifetime' event (Muller, 1993). Consequently, GIS teachers have developed computer-based materials for learners at all levels, from school students to postgraduates, and for the independent professional updating their skills and knowledge. To date, these materials have followed a number of approaches. Initially demonstrations of GIS software and its capabilities addressed the need to increase awareness of GIS and its applications (DoE, 1987). Arcdemo (Green, 1987) was an innovative early example, providing a demonstration of the software package Arc/Info on- 
line. Training in particular software, and the need for hands-on experience, have been addressed with the production of software-specific educational materials which use primarily traditional text-based instructions for exercises with specially prepared data. Examples include Getting started in GIS (Langford, 1993), the Unitar workbooks for Idrisi (for example McKendry et al, 1992) and Understanding GIS: the Arc/Info Method (ESRI, 1990). These have proved particularly popular, and by directing learners through structured exercises allow new users to become familiar with complex software in a relatively short time. More recently, they have migrated to CD-ROM, with training materials such as Getting to know Arcview (ESRI, 1995) provided in this format, and combining software, data and demonstrations.

However, the learning path in most of these cases is prescribed, and individual exploration of the software and data restricted. More interactive tools for the delivery of a broader GIS curriculum include GISTutor, the commercially successful computer-based tutorial developed by Raper and Green (1992). GISTutor is completely independent of GIS software, offering animation of some operations, and illustrations of others as a tutorial and reference resource. This interactive GIS Encyclopedia does not attempt to manage or structure learning, and the lack of colour graphics is a drawback. More recent computer-based tutorials include SITE (Spatial Information Tutorial Environment), which offers structured routes through a tutorial hosted on a Unix workstation (Wood and Langford, 1993), and the prototype Color your World (Sutton and Van Zuyle, 1994) which aims to teach political geography while familiarizing school students with GIS. The latter uses a computer games approach.

In the field of professional education the use of tutorials and emulators is becoming more common. Computer-based tutors specific to certain topics and software products are emerging. For example, in GIS, tutorials for Arc/Info and Idrisi software are accessible via the Internet (ESRI, 1996; Lorup, 1996). These still require users to have access to the software themselves. Perceiving the difficulty of providing a whole class with expensive high technology equipment, the US Defense Mapping School have created an innovative tutorial and simulation system for a related technology, the Global Positioning System (GPS) (Thompson, 1996).

Most of these learning tools can be categorized as computer-aided instruction. They offer controlled exploration of the data and resources, with limited opportunities for feedback and discussion. While this may suit the situation of the learners they are designed for, which is normally a classroom situation with tutors on hand to assist, there is also a need for computer-managed learning tools for the mature GIS learner, based at home or work, and studying alone. The GPS training package (Thompson, 1996) may also go some way to meeting the needs of professional updaters, and has been designed to fit onto 3.5 inch floppy disks so that learners can take a copy home as a reference source.

Many suggestions have been made for improving computer-based tutors and instructors. Thompson (1996) looks forward to the inclusion of full multimedia audio and video in the GPS tutor, hampered at present by the resources available to his students. He also sees the final goal of the system as allowing students with no background in the subject to train themselves in the use the technology. One problem noted is the need for constant updates in a continually evolving technology. In more general terms, Harrison (1993) stresses the need for computer-based tutorials to 'delight the student' since they can be 'inflexible, 
unadaptive and tiresome'. Gold et al (1991) identify a role for Intelligent Tutoring Systems which overcome the primitive nature of much computer-based instructional material, and help the learner to identify and treat learning difficulties and to adjust to different levels of knowledge. There have also been calls for CAL materials that allow learners more control over their learning, both in style and content. Clarke (1993) divides learners into those who prefer structured, guided instruction, and those who seek unstructured discovery learning. He offers these two extremes as models for the development of CAL materials that allow students to choose how they wish to learn.

The experiences of Unigis, providing postgraduate distance-learning courses in GIS since 1992, has shown that learners on their own at home face particular difficulties with computer-based learning resources, since problems cannot be solved by the simple raising of a hand in a classroom or by a knock on the tutor's door. Feedback, communication and efficiency are important factors affecting motivation and learning for distant students, and learning packages must be appropriate to the resources they have available. These issues have guided the design of the Unigis Learning Station, a multimedia computer-managed learning package.

\section{The context for the Unigis multimedia Learning Station}

Unigis is an international network of universities offering postgraduate diploma and MSc courses in GIS which are based on a common curriculum, adapted and translated to meet local student needs. The students on Unigis courses are mainly mid-career professionals from the whole range of GIS application areas. In mid-1996 there were over 300 students registered on Unigis courses, making this one of the largest programmes of GIS education world-wide. To meet the needs of Unigis students, careful attention has been given to methods and procedures for course delivery, feedback and assessment. There are special problems involved with the delivery of such a technical and practical subject as GIS by distance learning, and from the outset there was some scepticism as to whether the course would succeed. Full details of the course, including an evaluation of strengths and weaknesses to date can be found elsewhere (Reeve et al, 1993; Reeve et al, 1994; Petch et al, 1994). The course curriculum is outlined briefly below in order to provide the context for the design of the Learning Station.

The Unigis curriculum is designed around the theme of database and GIS project design and management. The aim is to provide the skills and knowledge necessary to be a successful GIS manager, not to train GIS technicians who may need to be competent in several programming languages and a range of GIS systems. Muller (1993) highlighted the neglect of the management component of GIS education and the need for personnel with an appreciation of the human factors of GIS. The course hopes to address this need by the inclusion of topics such as system design and management and the organizational impacts of GIS, in addition to more technical subject areas.

A series of modules, designed to be studied in sequence, make up the basic diploma course. These have recently been reviewed, following five years of operation of the course, and are outlined in Table 1.

This basic model has been developed to meet local needs, with international partners adapting exercises for local students and offering support in different languages. In the 
Sarah Comelius and lon Heywood An interactive learning environment in Geographical Information Systems

\begin{tabular}{|lll|}
\hline & Module number & Module title \\
\hline Unit I & 0 & Course induction* \\
Unit 2 & 1 & GIS:An overview \\
& 2 & Spatial data \\
Unit 3 & 3 & Database theory \\
& 4 & Spatial operations* \\
Unit 4 & 5 & Data sources \\
& 6 & Data acquisition \\
Unit 5 & 7 & Concepts for spatial thinking \\
& 8 & GIS in organizations* \\
(Any two from the list may be & 10 & Project management \\
chosen. Only one of Modules II & 12 & Database theory II \\
and 12 may be studied.) & 13 & ArcView applications \\
& 14 & Maplnfo applications \\
& & Remote sensing and GIS \\
& & Visualization \\
\hline
\end{tabular}

Table 1: Unigis diploma modules

UK, the modules are mailed to students and are completely self-contained. Each one incorporates notes, reading materials, activities and exercises of various types. Activities and exercises may be computer-based since all students are required to have access to GIS and database software. They may include browsing through a computer-based storyboard or the manipulation of data in a database. Self-assessed exercises are provided for active learning and for revision at the end of major sections of text. Tutor-assessed exercises are also a part of each module, and these may involve report or essay writing, data analysis or another appropriate activity. Assessment is entirely by coursework. Module materials are comprehensively updated with each new intake of students.

Optional residential workshops are available as an introduction to the course and for additional hands-on experience and group activities, as well as interaction and discussion with other students and staff. Students also receive a comprehensive set of administrative information which includes a course study guide, a course handbook (containing timetables, staff profiles, course regulations, etc.), intermittent course newsletters, and other relevant material. Currently these documents exist in paper form and are sent to students by mail.

\section{The design of the Unigis Learning Station}

The previous section indicates that there is currently a mix of textual and multimedia materials used for course delivery, a substantial body of information that requires regular updating, and materials which can be easily computerized. Users require non-linear access to course information, and have the skills and the resources to access and use computerbased resources. Thus, the course meets some of the criteria used for the evaluation, offered by Woodhead (1991), of whether a hypertext tutorial package is appropriate in a given learning situation which can be directly applied to multimedia. As a further justification for the adoption of a multimedia computer-based learning resource, the use of enabling technologies such as hypertext allow teaching to be more easily matched with 
learning style (Ellis et al, 1993), which, in turn, improves motivation for learning, highlighted earlier as an important consideration for a distance-learning course. Initially, discussions among the course teaching team identified a range of issues for the Learning Station to address. Six of these are outlined below.

\section{Technology training}

The course requires a wide range of information-technology skills, including familiarity with operating systems, how to start and use the course software, and how to load and run data sets and storyboards. For students who are relatively new to information technology, this may be a steep learning curve, particularly given the range of interfaces found in GIS and related software. The Learning Station helps to overcome some of these initial problems by using a straightforward interface. The need for clear and consistent interfaces for computer-based learning materials in GIS has been recognized (Wood and Langford, 1994), and there are comprehensive guidelines which can be adopted (for example Clarke, 1992) to help provide an appropriate interface. However, the Learning Station interface does not discourage students from finding their own way around course GIS and database software, and running these as separate packages.

\section{Isolation}

Distance-learning students can feel isolated and demotivated. To address issues of isolation and support, the Learning Station promotes electronic mail links with the course team and other students. A help facility in the Learning Station, which includes the dispatch of email queries directly to the course team or peers, is planned, and this will encourage communication and assist the provision of a fast help-line service. Digital versions of course documentation are already available, offering rapid easy-to-access help. Encouragement to use electronic communications for the diploma will also benefit students going on to undertake independent Masters research projects by allowing access to the Internet, library catalogues, and tutors and experts. The social support, help with work scheduling and opportunities for professional networking offered by computer conferencing are now recognized as important supplements to the academic support such a system can offer (Hartley et al, 1991).

\section{Management of course materials}

To assist students with the management of their learning, and to ensure the efficient use of study time, a third aspect which the Learning Station addresses is the management of course materials and personal progress monitoring. This includes, for instance, functions to automatically load new exercises and storyboards. Thus, each module should arrive with new data which can be added into the Learning Station. This offers advantages for academic staff, since student progress can be controlled by the distribution of modules in sequence. For students, the repeated loading of separate data sets, exercises and storyboards with each new module is simplified, and data can be deleted once they have been finished with. To help with the management of assessments, the Learning Station provides a common framework for assessments, and should, in future, allow students to check the completeness of submitted work. Where computer-based materials are required for submission, the Learning Station could assist with the preparation of these (by facilitating, for example, copying to disk, checking for completeness, or the emailing of results to academic staff). 
Feedback and assessment

Feedback and assessment are paramount with a distance-learning course where contact with tutors is necessarily limited. Instant feedback is particularly difficult, other than by the inclusion of answers for self-check tests and exercises within modules. To increase the opportunities for students to obtain feedback on their progress, computer-marked tests are included in the Learning Station. These enable students to secure faster feedback on learning and problems as they work through the modules. Where problems are identified, suggestions for further reading, or pointers to appropriate sections in the course texts can be included. The Learning Station also provides students with the ability to track submission dates and record grades for tutor-assessed assignments, enabling progress to be monitored throughout the course.

\section{Learning resources}

Learning resources are an issue, since libraries, databases and literature are out of reach for many distance-learning students. The Learning Station offers links to a range of additional study materials to help the creation of an effective integrated study environment. These include a comprehensive reference database, glossaries and indexes, the course newsletters and technical help guides for course software. Instead of a range of paper documents and computer databases, the Learning Station allows access to all of these, and links between them as appropriate. Access to resources available through the Internet (such as up-to-date discussions of GIS topics, data, standards documents and other information difficult to come by in such a fast moving discipline) and through electronic communications provide additional learning opportunities.

\section{Virtual workshops}

Reeve et al (1994) recognized that the original requirement to attend residential workshops was a deterrent to some overseas applicants, and the course has now been reviewed to make such workshops optional. This is seen as a problem for some students, limiting opportunities for face-to-face contact with staff and other students, and for group working. However, some of the current workshop activities and materials would be suitable for inclusion in the multimedia Learning Station. For example, audio tapes of discussions with guest experts and video-conferencing sessions could address the workshops' original aim to expand input from professionals in the GIS field, and the promotion of discussion between students and experts. Exercises and tutorials, including those designed for group participation, can be addressed through the Learning Station with electronic communication links providing for group discussion and sharing of data and ideas. Heywood and Reeve (1995) address these issues further.

The above list is, in part, still a wish list, since some of the functions required are currently technically challenging, and would create a Learning Station which would not run on the average home-based computer. So, through questionnaire surveys, feedback sessions at workshops and informal contact, the Unigis-students have helped the course staff to identify four main functions for the Learning Station which are the focus of the original design of the system and the discussion which follows. These four roles are:

- Adviser - the system should be capable of providing advice on practical matters including hardware requirements, common software problems and academic matters such as course regulations; 
- Informer - the system should provide easy access to up-to-date information such as course newsletters, deadlines for assessed work and dates of workshops;

- Assessor - the system should give immediate feedback on learning and provide selfassessment opportunities; and

- Tutor - the system should provide access to software tutors, demonstrations of new topics and access to 'real-life' tutors.

\section{Construction and development of the Learning Station}

The Learning Station is regarded as a learning management tool, not simply an instructor or computer-based tutor. Thus, using the definition of computer-managed learning provided by Gold et al (1991), it is software that aims to manage both conventional and computer-based learning. This is achieved by linking computer-based instruction tools, GIS and database software, communications software and specifically developed tools for the management and structuring of learning. These are designed to be used in conjunction with the paper text. The Learning Station is not designed to be a multimedia version of the modules already produced in paper form. It is a semi-structured, managed, learning environment that allows students control, flexibility in approach and the ability to monitor their own progress.

The framework for the Learning Station has been constructed using Multimedia ToolBook CBT. One of the criteria for development has been that the Learning Station should run on a relatively low specification PC under Windows. However, recognizing the rapid developments in telecommunications, and the decreasing cost of PC hardware, the development environment has had to be able to take advantage of future enhancements in these areas.

Most current students do not have access to a modem and the Internet, so the Learning Station has to offer all that is necessary to complete the course, including administrative information, exercises and access to software and databases. If communications are available, then access to Internet resources exist. Material is organized in two main sections: the Information Guide, and the Module Guide. A help system, including Learning Station tutorial and navigation map, are also provided.

Given the high standard of many existing CAL resources in GIS, it is part of the Unigis philosophy to include these where possible and appropriate as part of the tutor role for the Learning Station. Thus, links to existing resources produced by Unigis team members (such as a map algebra tutorial produced by Josef Strobl and a 'House Hunting' game produced by members of the UK team) have been developed. Links to other external resources, such as the Idrisi tutorial package Getting Started in GIS (Langford, 1993), the Microsoft Windows tutorial and a range of GIS demonstrations produced by other third parties, are provided. However, it is important that such links remain easy to change since demonstrations and exercises date quickly as software changes.

The Learning Station uses a variety of different software tools including hypertext, animation, interactive question and answer software, commercial GIS and database software and communications software. Hypertext has been used for many aspects of the Informer and Advisor roles required, including the presentation of course guides, handbooks and help systems. The inclusion of the complete module texts as hypertext 
documents is a development option. However, this is not favoured by the majority of students who prefer paper notes which can be studied and annotated at any location. Summary details for each module are, however, included. Animation is a useful tool for the demonstration of complex and time-consuming GIS operations, as has been demonstrated by GISTutor (Raper and Green, 1992). In the Learning Station, it has been used for tutorial and storyboard type displays of operations that are not effectively illustrated on paper. ToolBook has been used to construct a set of self-check questions of a multiplechoice and short-answer nature. These are ideal for self-assessment exercises and provide immediate feedback and suggestions for further work where problems are identified. With the paper versions of the module, this type of feedback was missing, and this meets the need for an assessor role for the Learning Station suggested earlier. Access (Microsoft), dBase (Ashton Tate), Idrisi (Clarke University) and Arcview (ESRI) are currently used by Unigis. The Learning Station provides links to these where they are required for the visualization of case-study data sets and for the completion of exercises or assessments.

Initially a pilot Learning Station was produced for one module, half-way through the course. Material was then developed for all course modules. A typical module includes:

(i) Automatic loading of exercises and data from disks which arrive with paper-based materials.

(ii) Self-assessed exercises. A variety of approaches to multiple choice questions have been implemented to elicit comment from users as to which suit their learning styles most effectively.

(iii) Computer-based tutorials. For example, a short tutorial offering animation of common map algebra functions in raster GIS has been adapted from a German language tutorial written by Josef Strobl. This supplements static text-based diagrams very effectively.

(iv) Annotated stories and virtual lectures. Slide shows of computer screens illustrating case-study data sets, referred to within the text, offer substantial advantages over paper-based reproductions of images. In a similar way, virtual lectures, supplementary notes and diagrams and self-check tests written to supplement module and workshop materials have been included.

(v) Tutor-assessed exercises. Details are annotated with the help of icons into aims and objectives, deliverables and methods sections. Over the paper text these have the advantage of added visual impact, and direct access to the data and software required, including word-processing software for report writing.

(vi) Supplementary learning resources. These may include sample Internet pages or suggested Internet sites for exploration. The Learning Station also offers access to a comprehensive reference database that has been compiled by course staff.

Future developments for the Learning Station include the creation of a more comprehensive virtual classroom. Virtual lectures, including notes, diagrams and self-check tests have already been provided, and the idea of a virtual workshop, involving collaborative problem-solving and multimedia presentations has been explored (Reeve and Heywood, 1995). 


\section{Evaluation of the Learning Station}

Two cohorts of UK based students have been surveyed using a comprehensive questionnaire addressing resources available to the students, use of the Learning Station, attitudes to the Learning Station and learning styles. Results from the evaluation are presented as follows:

Group $A$ - These students supplied initial impressions of the Learning Station. Group A consisted of representatives from two separate cohorts of students. First, there was a sample of students from one cohort who were exposed to the Learning Station mid-way through the course where it was presented as a development in course materials. Also in Group A were a second set of respondents from a second cohort who evaluated the system after completing the first module.

Group $B$-These students were more familiar with the Learning Station. Group B consisted of students from the second cohort surveyed, re-surveyed mid-way through the course.

Comments from Group A were mixed, although the majority were in favour of the system, and those not provided with the Learning Station at the start of the course commented that it would have been useful to have the system available throughout. In total, 21 students provided full feedback as part of Group A. All of these had used a computer prior to the course (predominantly for word processing). Over 40 per cent obtained a computer (usually a 486) for the course. Over 90 per cent felt that the Learning Station could become an essential part of the course, and more than 60 per cent felt that it encouraged greater autonomy and self-direction in their learning. Over 60 per cent disagreed with the statement that the Learning Station was a gimmick. The feedback from the students is considered in terms of the four roles identified for the Learning Station.

(i) Adviser - about 50 per cent of the students used the Learning Station to access information from the course handbook, and other technical information (particularly information on communications and the Internet). Some respondents felt that more details were required in these areas.

(ii) Informer - again, about half of the students used the Learning Station in this role. They looked particularly for recommended texts, the newsletter and dates of deadlines and workshops. They commented that information provided should be up to date and relevant, and suggested that tutors should provide regular updates. They wanted to see a full reference database and to have, if possible, direct access to reading materials. They felt that the Learning Station helped make information easily and readily accessible.

(iii) Assessor - the students surveyed used the Learning Station most frequently for undertaking self-assessment exercises. They found these exercises easy to use, and felt the system improved the learning process. Less, just under half, felt that the Learning Station provided helpful feedback or information on progress.

(iv) Tutor/motivator - the Learning Station offered interactive demonstrations and slide shows to illustrate some of the more graphical elements of GIS, and case studies. Students felt these were useful backups to the text, although in places they felt that more details would have been useful.

Respondents were also asked about positive and negative aspects of the Learning Station. 
In general the positive points included easy access to course material and software, graphical shows and visual presentation of material to back up issues covered in the paper text. The self-assessed exercises again scored highly. Several individuals commented on the positive aspects for learning. For example, it was suggested that the Learning Station provides an alternative source of study - 'a change is as good as a rest' - and that the Learning Station assisted learning by doing and provided motivation for learning.

Negative points and suggestions for developments focused on technical problems, and interestingly, the problems of reading text on-screen. Some students had faced technical problems with the setting up of the systems on particular machines. They requested a Print Screen facility and full help system. In addition, the need to read large chunks of text from the computer screen was felt to be far from ideal - the font used was criticized, as was the nature of the presentation, particularly the use of windows with scroll options. One user commented that the system made it impossible to browse through text, but required the reader to wait for the computer. Others were concerned about the fact that they did not want to spend more time in front of the computer screen.

Group B, consisting primarily of the same students surveyed half-way through the course, offered an interesting re-evaluation of the Learning Station once they had had time to fully assess its role in the course. Twenty-six students provided feedback on Modules 3, 4 or 5; most were working at the time, and all were attendees at a residential workshop. Figures 1 and 2 give an indication of the amount of time these students have devoted to using the Learning Station. For the first three modules, the Learning Station was used most often for between one and five hours. For module 4 , which was completed by a smaller number of students (hence the high zero-hours use category), the amount of time being spent with the Learning Station increased to 6-10 hours. This may be due to the nature of this module, which involves extended work with the computer, and if software used is accessed through the Learning Station rather than directly from the operating system, this would put the overall time of use up much higher than for previous modules.

The roles of the Learning Station - Advisor, Informer, Assessor and Tutor - again make a good framework for evaluation of the use of the system:

(i) Adviser - 58 per cent of the students used the Learning Station to access information from the course handbook and contact information. This use of the Learning Station for contact information had become more or less routine for some students who felt that it was useful to have all this information in one place, and that the system acted as a kind of Filofax for the course.

(ii) Informer - the use of the Learning Station in this role had decreased. Students accessed deadline dates and a couple commented on the loss of the course deadline calendar during one Learning Station update. The need for up-to-date information, and increased amounts of information, were still concerns; students still felt there were gaps in the material provided, and sometimes found that information they would have liked was not available.

(iii) Assessor - the students surveyed were still using Learning Station most frequently for undertaking self-assessment exercises. Over 90 per cent undertook the self-assessed exercises provided, although fewer used the Learning Station for help with the tutor-assessed work. The electronic quizzes were still a highlight of the system for several students. 


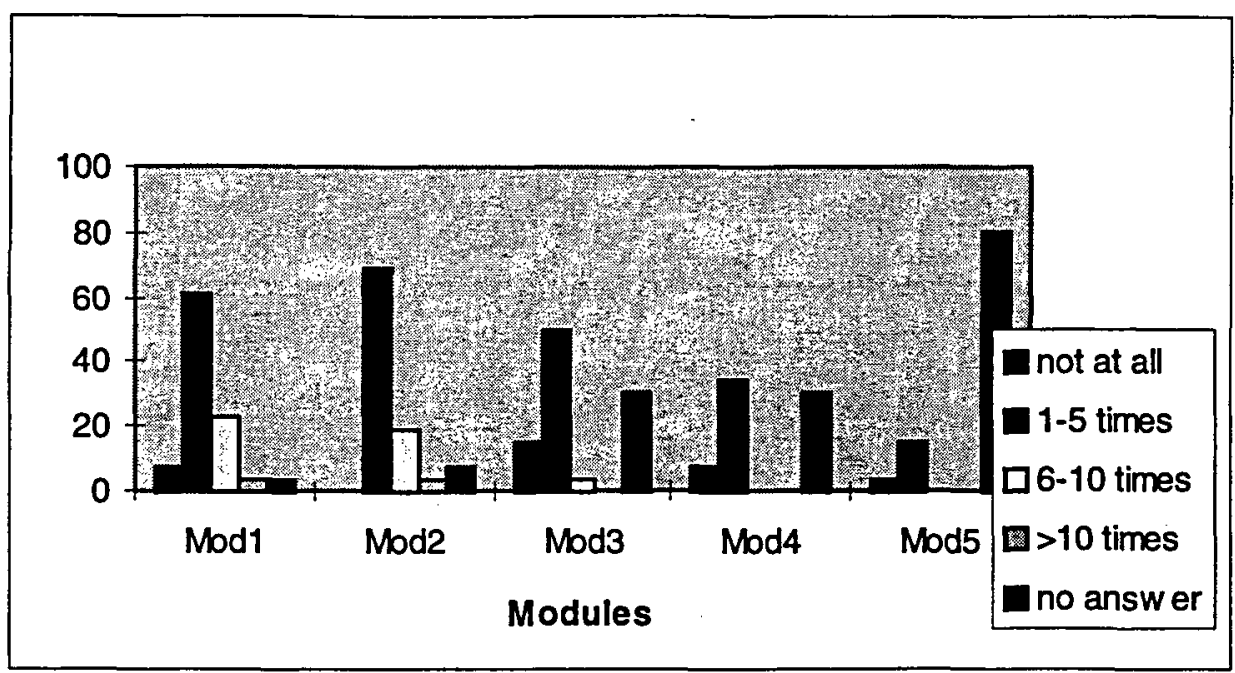

Figure 1: The number of times the Learning Station was used by surveyed students

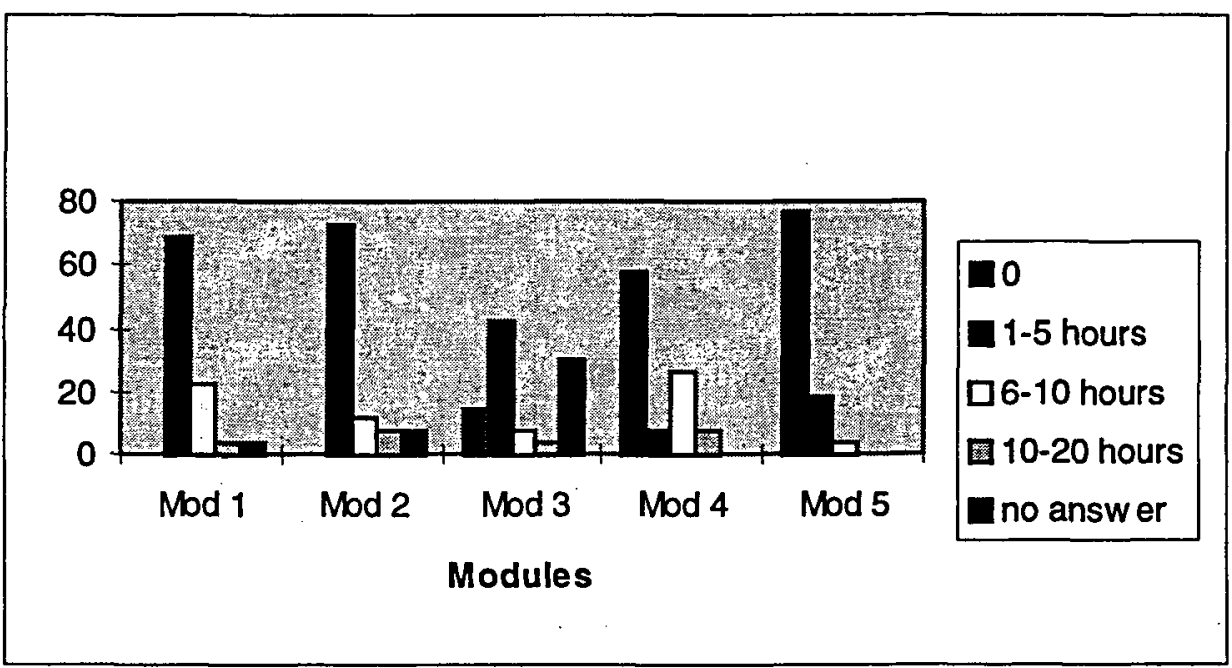

Figure 2: The number of hours the Learning Stotion was used by surveyed students

(iv) Tutor/motivator - the limitations of some of the interactive demonstrations and slide shows were now criticized; some felt these were of limited content and often needed fuller explanations. However, the slide shows and graphics in the Learning Station were still a positive aspect for many students.

Negative aspects this time strongly focused on three issues. Firstly, and most significantly, students had had problems with installation of updates to the Learning Station, with running software, and with bugs in the software. This may partly be due to the limited installations options available (the Learning Station was designed to run in a specific 


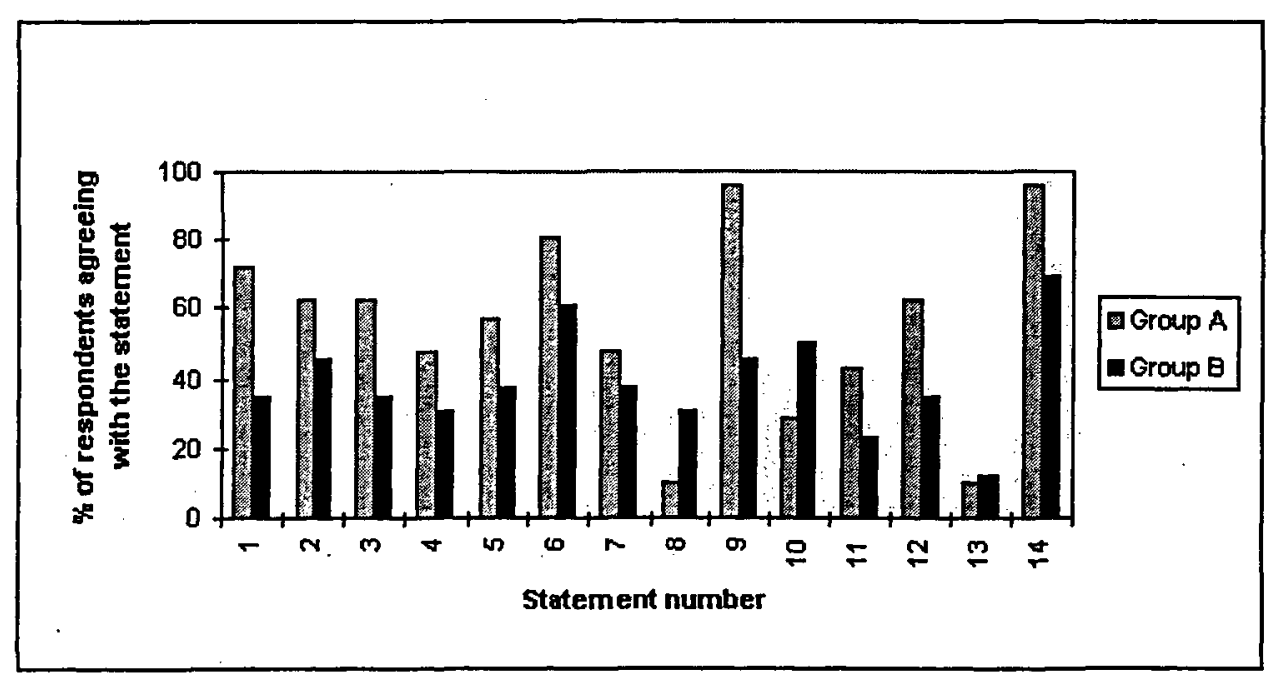

Key to statements:

The Leaming Station:

I helps leam about course materials

2 helps understanding of course materials

3 helps provide extra ideas and materials

4 helps provide feedback on progress

5 helps provide motivation for learning

6 helps improve learning process

7 is more convenient than telephoning a tutor

\author{
8 is time-consuming and frustrating \\ 9 provides useful course information \\ 10 is a poor substitute for face-to-face communication \\ 11 increases my motivation to learn \\ 12 encourages greater autonomy and self-direction \\ 13 is a gimmick \\ 14 could become an essential part of the course
}

Figure 3: Attitudes to the Learning Station

directory structure on the $\mathrm{C}$ : drive), and as students gained in confidence with the course software they wanted to install it on different machines, and on different drives. However, many of the problems may have been due to the need to keep up with a punishing production schedule to ensure that computer-based materials were available with each module. Despite testing on several different PCs before dispatch, problems still appeared to arise. In addition, software copying was done by an external reprographics firm, and occasionally problems originated at the disk-copying stage. Students also criticized the amount of hard-disk space the system was requiring.

A second set of issues related to the information provided. Many students felt that there were still gaps in what was available, that the Learning Station was not as informative as it could have been, and that access to additional resources, such as complete journal articles, would have been useful. Finally, students commented again on the interface, feeling that it was a little cumbersome, with odd navigation, a few typing errors and unclear exit route.

Figure 3 illustrates changes in attitude towards the Learning Station between Groups A and B. Whereas Group A were highly positive towards the Learning Station, opinions seem to have mellowed over time, and Group B were in almost all cases less likely to agree with the statements in the survey which emphasized the positive aspects of the system. For example, the percentage agreeing with the statement that the Learning Station provides useful course information dropped from well over 90 per cent to just over 50 per cent; and 
those agreeing that the Learning Station helps to learn about course materials decreased from over 70 per cent to approximately 35 per cent. At the same time, the second survey group were more likely to agree that the Learning Station is a gimmick (increase from 10 per cent to 12 per cent), that the Learning Station is a poor substitute for face-to-face communications (increase from 29 per cent to 50 per cent), and that the Learning Station is time-consuming and frustrating (increase from 10 per cent to 31 per cent). These changes in attitude may well be linked with the technical problems outlined above, with the lack of information on all topics available, and general familiarization with the system leading to a realization that it is not there to solve all student queries and problems. The need for faceto-face contact, or direct communication, was also flagged, revealing that the students still need the motivation of tutor and colleague support. Allied to this were comments about the use of email by staff, who did not always respond quickly enough.

\section{Issues for development}

A number of challenges face the development of the Learning Station. Some of these have been outlined in Cornelius et al (1994); others have become apparent from the results of the above evaluation.

Resources appear to be the primary issue for both students using the system and staff involved in development. From the development point of view, the need for sufficient resources for development itself, for testing the system before dispatch, for quality control and rapid communication of problems to students, is clear. For the Unigis courses, the Learning Station was developed initially by a small team, with a full-time programmer being brought in to implement the system throughout the course. Resources had to be found to fund the programmer post, and the rest of the course team had to be encouraged to participate in the development of the system to ensure that all modules had links to the Learning Station. There are other resource implications which affect these and similar developments of digital course materials. Obtaining permission to use resources developed elsewhere in the Learning Station is a time-consuming process, often expensive, and often, where materials are in digital format, or published on the Internet, difficult to pursue.

From the student point of view, the Learning Station is expected to be a comprehensive reference source. Given the difficulties of a fully stretched course team keeping to production deadlines, perhaps one way to address this requirement is for the students themselves to contribute to some of the information sections of the Learning Station.

Hardware and software resources are another issue. The pace of technological developments in multimedia, the Internet and related areas is exciting and challenging. However, there is a wide gap between what is technically feasible and what will work for students at home. This is illustrated by the situation as regards electronic communications. Despite wide use in the academic community, they.are less well used in many organizations. Just under one third of the 1995-1996 cohort of UK-based students were on email, although the figure was higher for centres in other countries such as Austria. Most UK students are new to email and the Internet, and to allow time for experience and skills in this area to develop, the electronic communication part of the Learning Station is currently an optional extra. However, given the pace of current development and the increasing availability of local access to Internet providers, electronic communications are considered by 
course providers as likely to be essential in the near future. Interestingly, however, the same opinion is not prevalent among students. Only a small minority of students are very much in favour of the use of the Internet and email, and suggest, for example, that the Learning Station has been eclipsed by the Internet, or that much of the contact information on the Learning Station could be presented on the Internet to help save hard-disk space on home PCs. However, there is still a proportion (16 per cent of those from Group B who have email) who do not think it should be made a compulsory requirement for students to have access to email.

The costs of some of the multimedia technologies are still prohibitive for some students on a course of this nature. CD-ROM, for instance, would be ideal for the storage of included articles, and videos of case studies and discussion sessions, and is therefore a development which will be built into the Learning Station in anticipation of falling costs. Access to CDROM is likely to become a requirement for students on the Austria-based courses since there are examples of externally produced data sets, conference proceedings, and software demonstrations already available on CD-ROM which are ideal resources for the diploma. It seems likely that developments in PC technology and operating systems and rapidly falling costs will help to promote home computing in a more general manner, thus placing the resources required within easy reach of all Unigis students in the near future.

There is also the more fundamental question of whether the quality of the learning process will actually be improved by the availability of a computer-managed learning tool such as the Learning Station. Will it improve or impede learning? Some findings, for example Mason (1994) and Goodyear (1994), suggest that learning and motivation will be significantly improved for distance learning students through interaction with course materials, and particularly through increased communication with staff and other students. From the evaluation of student attitudes, it is clear that different students have different experiences with the Learning Station. However, encouragingly, after almost half of the course, there is still a high proportion who feel that the Learning Station helps to improve the learning process (61 per cent) and is an essential part of the course (69 per cent). Lower percentages agree that the Learning Station helps their understanding of course materials ( 46 per cent) or helps to provide motivation for learning ( 38 per cent). The challenge for the Learning Station development appears to be to produce a system which will continue to 'delight the student' throughout his or her studies, while preventing frustrating technical hitches and providing full and appropriate information to meet student requirements.

\section{Conclusion}

The Learning Station develops earlier ideas for computer-based tools for GIS education, and the methods being adopted are applicable to a wide range of GIS educational situations, including undergraduate resource-based learning, and professional updating. For Unigis distance-learning students there is a clear need for the computer to act as advisor, informer, assessor and tutor, since these students are outside the traditional classroom environment. The existence of current computer-based materials in a variety of formats which can be adapted and developed to meet these needs within a multimedia framework supports the development of the Learning Station. The Learning Station approach proposed offers the opportunity to co-ordinate the wide variety of computer- 
based tools, including electronic communications, animation, existing CAL packages, and GIS and other software, which are already being used in the course. Learning-management tools like this, which offer more flexible and effective GIS education, will help to meet the challenges of life-long education in a complex and fast moving discipline such as GIS if resources are available to developers, tutors and students, and if innovative materials can be continually developed and updated to meet student needs.

\section{Acknowledgements}

The authors gratefully acknowledge the assistance of Josef Strobl, James Oliver, Steve Tomlinson and Hong-Mei Wu with the development of the Learning Station. Jim Petch, Derek Reeve, Nigel Trodd and Christine Warr have provided materials for inclusion in the Learning Station. Helpful comments have also been received from Unigis staff and students throughout Europe. An earlier version of this paper was presented at ED-Media 96 and appears in the proceedings of that conference as Cornelius and Heywood (1996).

\section{References}

Cornelius, S.C. and Heywood, D.I. (1996), 'The Unigis Learning station: an interactive learning environment for distance learners in geographical information systems', Proceedings of the 1996 World Conference on Educational Telecommunications, Boston MA: AACE, 74-9.

Cornelius, S.C., Heywood, D.I. and Strobl, J (1994), 'Professional development and multimedia: the development of a GIS Learning Station for the Unigis Diploma Programme', Proceedings of GIS/LIS 94, USA: ASPRS, 181-90.

Clarke, A. (1992), 'The principles of screen design for computer based learning materials', Learning Methods Project Report OL121 (2nd edition), Sheffield: Employment Department.

Clarke, J.A. (1993), 'Cognitive style and computer-assisted learning: problems and a possible solution'. ALT-J,1 (1), 47-59.

DoE (Department of the Environment) (1987), Handling Geographic Information: Report of the Committee of Enquiry chaired by Lord Chorley, London: HMSO.

Ellis, D., Ford, N., Wood, R., Clarke, D., Smith, G. and Griffiths, A. (1993), 'Hypertext and learning styles: optimising the effectiveness of training software', Learning Methods Project Report OL148, Sheffield: Employment Department.

ESRI (1990), 'Understanding GIS: The ARCIINFO method', London: Longmans.

ESRI (1996), http://www.esri.com.

Goodyear, P. (1994), 'Telematics, flexible and distance learning in postgraduate education: the MSc in Information Technology at Lancaster University', The CTISS File, 17, 14-19.

Gold, J.R., Jenkins, A., Lee, R., Monk, J., Riley, J., Shepherd, I. and Unwin, D. (1991), Teaching Geography in Higher Education: A Manual of Good Practice, Oxford: Blackwell.

Green, N.P.A., (1987), 'Teach yourself geographical information systems: the design, 
creation and use of demonstrators and tutors', International Journal of Geographical Information Systems, 1, 279-90.

Harrison, C. (1993), 'The role of learning technology in planning change in curriculum delivery and design', $A L T-J, 2$ (1), 30-7.

Hartley, J., Tagg, A., Barger, B., Barry, D. and Fitter, M. (1991), Computer Conferencing for Distance Learning: Final Report to the Learning Technologies Unit of the Department of Employment, London: Birkbeck College.

Heywood, D.I. and Reeve, D.E. (1995), 'Close contact with distant students: the potential of on-line learning in the InterGIS Diploma Programme', Proceedings of the Joint European Conference on Geographical Information, volume 2, 354-9.

Langford, M. (1993), Getting Started in GIS, University of Sheffield: CVCP/USDU.

Lorup E. (1996), http://www.sbg.ac.at/geo/idrisi/tuthome.htm.

Mckendry, J.E., Eastman, R., St Martin, K. and Fulk, M.A. (1992), Applications in Forestry (Explorations in GIS Technology, volume 2), USA: UNITAR/Clarke University.

Mason, R. (1994), 'Computer conferencing and the Open University', The CTISS File, 17, 5-7.

Muller, J.C. (1993), 'Latest developments in GIS/LIS', International Journal of Geographical Information Systems, 7 (4), 293-303.

Petch, J., Cornelius, S., Heywood, I., Briggs, D. and Reeve, D. (1993), 'Postgraduate distance learning in GIS' in Green, D.R., Rix, D. and Cadoux-Hudson, J. (eds.), Geographic Information 1993 (The Yearbook of the Association for Geographic Information), London: Taylor and Francis.

Raper, J. and Green, N. (1992), 'Teaching the principles of GIS: lessons from the GIS Tutor project, International Journal of Geographical Information Systems, 6 (4), 279-90.

Reeve, D.E., Briggs, D., Cornelius, S., Heywood, I. and Petch, J. (1993), 'Distance learning: a viable approach to traditional GIS courses?', EGIS 1993 Proceedings (1), Utrecht: EGIS Foundation, 843-51.

Reeve, D., Kusse, B., Petch, J. and Strobl, J. (1994), 'The Unigis postgraduate network: a SWOT analysis', EGIS 1994 Proceedings (1), Utrecht: EGIS Foundation, 533-7.

Sutton, P. and Van Zuyle, P. (1994), 'GIS Education with Arcview 2'. Proceedings of GIS/LIS '94, USA: ASPRS, 727-30.

Thompson, R.J. (1996), 'Simulating GPS: a DOD receiver training system', GPS World 7 (5), 38-46

Woodhead, N. (1991), Hypertext and Hypermedia, Theory and Applications, Wilmslow: Sigma Press. 